Discourse and Communication for Sustainable Education, vol. 5, pp. 22-30, 2014

\title{
Academic Library as the Space for the Development of Future Specialists' Competence
}

\author{
Laimute Kardeliene, Kęstutis Kardelis and Rima Bakutyte \\ Siauliai University, Lithuania
}

\begin{abstract}
The article discloses the value of academic library. This value is deriving from the university purpose to prepare students to be able to deal with the increasing the flow of information in the society (Owusu - Ansah, 2001). Research was carried out in Utena University of applied science. First-year students $(n=140)$ made $48,3 \%$ of the sample, and third-year students $(\mathrm{n}=150)-51,7 \%$ of the investigated sample; males $-33,8 \%$ $(\mathrm{n}=98)$, and females $-66,2 \%(\mathrm{n}=192)$. The conditions of academic library as student and future specialist empowered environment are validated: communicational, physical, pragmatic. The interpretation of research data disclosed that the academic library as learning environment and as environment which is empower the student to a professional qualification less or more improve future specialist professional, academically and as a personality. The future development of specialist competence effectiveness criteria can be considered as the nature of those experiences, which causes him to preparation for examinations and various settlements, preparation of projects and the search for the global academic community material created a topic of interest. The nature of experiences can reduce the educational impact of library. While improving learning environments are necessary to guide students with higher academic achievement and those who are spending more time in the library view.
\end{abstract}

Keywords: academic library, future specialist training, information literacy, experiences in the library

Western European and global tendencies focus our attention on the reality of the professional education of future specialists at higher education institutions in Lithuania. Since orientation towards effective activity on the working place is one of the features of the modern educational paradigm, students during their studies should develop in every possible way, i.e. both academically, professionally, and as personalities (Holmes, Hooper, 2000; Salmi, 2002). However in Lithuania, it is stated that the system of the education of specialists is practically not adapted to the needs of life-long learning, and the contents of the curriculum is insufficiently oriented towards the development of critical thinking, problem-solving, and informational literacy competences (OECD, 2002, Ilisko, Igatjeva, Micule, 2010; Salite, 2008). The level and the extent of the development of the global information society requires an educational response that would be focused 
on the usage of information rather than on the application of information technologies, i.e. there is a greater need for developing informational literacy rather than informational technological literacy (Johnston, Webber, 2003). In this context, emphasis is placed on the educational (and learning) environments (Lipinskiene, 2002; Prosser, Ramsden, 2003; Lea et al., 2003). Thus, attention is shifted to the library as a constituent part of the learning and educational environment of higher school (Jiao, Onwuegbuzie, 1999; Owusu-Ansah, 2001; Thompson et al., 2003; Jucevičienè, Tautkevičienè, 2004), which value, according to Owusu-Ansah (2001), stems from the higher schools aspiration to educate and train students who would be able to function in the society, and especially solve the problems that they may encounter.

This means that the task of higher shools is to provide resources for research and learning, since specialists and scientists have to know how to find and to select suitable information to be able to answer the questions and solve the problems that may arise in a changing environment; in addition to that, they need to know how to satisfy their expectations in a world with steadily increasing amount of information. This aspect of student education could be guaranteed by the best-prepared specialists of the academic community - the specialists of academic libraries. Thus, an academic library must be reorganized with the aim of creation such an institution that, besides the storage functions, would acquire the status of the learning field. Such position confirms that an academic library has reached new borders when speaking about its role in developing students' intellectual experience. This new role cannot be presented as only a part of the aim or mission of the library. Here it must be emphasized that the specific situation of a library, as well as its aims in general, typical of such situation, must stem from the experience of higher education (Owusu-Ansah, 2001). This show that an academic library and, most importantly, its specialists as the experts in the access to global information, its evaluators, analyzers, and managers, have potential possibilities for educating future specialists. For this reason, in the physical space there must be cooperation between librarians, scientists, and students, collaborating in the circulation of information useful for these partnership-bound participants of the educational and learning environment (Jucevičiené, Tautkevičienè, 2004).

The presented statements substantiate the relevance of the study and conditions the situation where higher education institutions of countries in transition experience the need for the analysis of purposive educational environments that would allow for the more effective and versatile academic, professional, and personal development of students.

The aim of the study was set: to determine students' approach to the conditions of the library as a learning environment, and to disclose the associations of this approach with the duration of studies, time spent in the library, and students' achievements.

\section{Materials and Methods}

\section{Participants}

The sample comprised 290 first- and third-year students from the Utena university of applied science. First-year students $(n=140)$ made $48,3 \%$ of the sample, and thirdyear students $(n=150)-51,7 \%$ of the investigated sample. In the aspect of sex, the distribution of the participants of the study was the following: males $-33,8 \%(n=98)$, and females $-66,2 \%(n=192)$. 


\section{Methods}

The attitude of the inquired students of the Utena university of applied science towards the conditions of the academic library as a learning environment was evaluated according to our self-designed questionnaire that consisted of five blocks. In each block, a combination of closed and open questions, and statements were presented. The first block - the block of social-demographical questions - consisted of the following independent variables: the subjects' age, sex, and year of studies. The questions of the second block were designed for the determination of achievement of the studies (a retrospective survey of the subjects' mean marks for the previous examination session). By including this question block into the questionnaire, we wanted to determine whether achievements in studies are related to the subjects' attitude to the conditions of a library as a learning environment.

The third block consists of the characteristics of a student as a reader. The characteristics were meant to identify what is typical of students as readers. The block consisted of the following questions: Are you a reader of any library? Which libraries' services are you using? How much time do you spend in a library (per week, per month, per term)? How do you react when other people offer you to get acquainted with newest information on the studied topic in books, newspapers, or journals? In addition to that, they were asked to evaluate they ability to search for information on the topic of interest; the evaluation should be performed using a 10-point scale (1 point - unable to search for information; 10 points - perfectly able to search for information).

The fourth block of questions was designed to determine the way students evaluate the conditions of library as a learning environment. In order to perform this task, the scale of the semantic differential was used. The scale consisted of 12 pairs of statements that name the manifestations of the conditions of a learning environment. The manifestations were coded on a scale from -2 to +2 (the most negative or positive evaluation). Having summed up the evaluation scores for each statement, mean score was calculated. The distribution was determined using factorial analysis; in addition to that the reliability and internal coherence of the statements of the scale were verified.

The factorial analysis of the questions from the aforementioned block allowed for the identification of three generalized types of conditions: the communication, physical, and pragmatic ones. The presented types explained $61.7 \%$ of the distribution of the manifestations of the conditions of the library as a learning environment: the first type $24.48 \%$, the second type $-20.14 \%$, and the third type $-17.08 \%$.

The verification of the internal coherence and reliability of the essential features of each type yielded sufficient values of Cronbach-alpha and determination coefficients: for the type of the communication conditions of the learning environment $-\alpha=0.69$ $(r=0.43-0.59)$; for the type of physical conditions $-\alpha=0.71(r=0.44-0.56)$; and for the type of practical conditions $-\alpha=0.63(\mathrm{r}=0.39-0.51)$.

The fifth block was designed to evaluate the aims of students' visits to the academic library. In this block, 38 statements were formulated as dependent variables of the study. The evaluation of the answers to the statements was performed using 5-point Likert scale: totally agree-agree - do not know - disagree - strongly disagree. 


\section{Research Procedures}

Students' inquiry was performed during the spring term of 2012/2013 academic year. The inquiry followed ethical and legal principles of research, and was based on the benevolence of the subjects. Students filled the questionnaires during seminar meetings. This activity was coordinated with the teacher in charge of the seminars. The filling of the questionnaires took 45 minutes. The inquiry during the seminars was performed by one of the researchers who explained to the students the aim of the study, presented the instruction on the filling of the questionnaire, and provided information on in anonymity of the findings of the study. In addition to that, the subjects were asked to answer the questions honestly and individually.

\section{Statistical Analysis}

The analysis of the obtained findings was performed using statistical data processing methods: Student's ( $t$ ) and Chi-square $(\chi 2)$ criteria, Mann-Whitney U test for the evaluation of the reliability of the differences in the findings of the study, Cronbach-alpha and determination coefficients for the determination of the reliability and internal coherence of the scale statements.

\section{Research Results}

The general mean of the examination session in the investigated students in 10point scale was $7.63 \pm 0.69$. The academic achievements of third-year students were higher: the mean of the evaluation of their examination session was $7.92 \pm 0.11$, while that of first-year students was $7.53 \pm 0.12(\mathrm{p}<0.05)$.

It is noteworthy that the absolute majority of the subjects $(91.4 \%$ of first-year students, and $94.6 \%$ of third-year students) visited only the academic library of their higher educational institution. In this aspect of the study, more visitors of the academic library were among females $(94.3 \%$ and $81.2 \%$; $<<0.05)$. Students' answers to the question about their reaction to somebody's proposal to get acquainted with the newest literature on the studied topic show that a greater part of the respondents $(43.4 \%)$ fathomed the proposition and tried to go to the library. Another part of the respondents $(33.2 \%)$ were less inclined to apply to other people, somewhat less $(11.7 \%)$ of them bought the recommended source of information, and the smallest part $(3.5 \%)$ of the subjects ignored the proposition because they thought that it was a triviality. Somewhat more $(9.2 \%)$ of the subjects indicated other ways of reacting towards such propositions, for instance: I find the information that interests me by myself through the sources that are familiar to me; I do not think this is the most important thing; or I listen to the proposition but do nothing.

Students were inquired about how highly (on a 10-point scale) they would evaluate their ability to perform the search for information on the topic of interest. The findings showed that the mean evaluation of this competence was $6.93 \pm 0.2$ points. The results of this test showed that females, compared to males, more highly evaluated their competence in this field: their mean rank value was 89.1 , while in males $-71.6(\mathrm{p}<0.05)$.

The mean duration of time per week spent in the library among the investigated students was $1.69 \pm 0.12$ hours, per month $-6.89 \pm 0.63$ hours, and per term $-23.1 \pm 2.14$ 
hours. The comparison of findings with relation to the year of studies showed that firstyear students spent more time in the library, compared to third-year students (first-year students spent, on the average, $28.4 \pm 2.9$ hours in the library per term, while third-year students $-14.3 \pm 2.1$ hours per term; $\mathrm{p}<0.001)$. This was typical for both males and females. The comparison of the time spent in the library with the mean evaluation of the last examination session showed that there was a tendency that those who study better spend more time in the academic library.

The subjects' answers to the fourth block of the questionnaire showed how they evaluated the conditions of the academic library as a learning environment. The findings showed that the majority of students chose the following characteristic of the library: this is a source of knowledge (mean evaluation $-1.34 \pm 0.09$ ) where precise information can be obtained $(1.09 \pm 0.06)$. It is noteworthy that over one-half of the subjects $(60.2 \%)$ chose the definition of the library as a working environment, whereas $18.3 \%$ of the subjects chose the characteristic of the library as a somniferous environment. It should also be emphasized that, among the presented evaluations of the library, $49.6 \%$ of the respondents defined the library as an environment with polite service.

It is noteworthy that $58.9 \%$ of the respondents highly evaluated the professional level of the library staff $-1.4 \pm 0.11$. The lowest evaluations were obtained for rational order $-0.85 \pm 0.09$, clear instructions $-0.7 \pm 0.12$, and fast service $-0.57 \pm 0.08$.

The questions of the fifth block allowed for the identification of two groups of students: those who study in the library (prepare for examinations and other tests) and those who only drop by (to change books or to make copies). Comparative data analysis showed that more critical evaluations of the manifestations of the conditions of the library as a learning environment were presented by students who come to the library to change books or to make copies (Table 1).

Table 1

The Distribution of the Evaluations of the Library Conditions in Groups of Students

Rank means in groups of students

Factors derived from the evaluations of (Mann-Whitney (U) test) Significance the manifestations of library conditions Those studying Those dropping level, $\mathrm{p}$ in the library by in the library

\begin{tabular}{lccc}
\hline Communicational conditions & 51.74 & 33.29 & 0.001 \\
\hline Physical conditions & 49.1 & 34.3 & 0.01 \\
\hline Pragmatic conditions & 54.47 & 31.8 & 0.001 \\
\hline
\end{tabular}

The study revealed an association between the communicational conditions of the library as a learning environment and the students' academic achievements (Table 2).

Table 2

The Manifestation of the Communicational Conditions in the Library In Relation to Students' Academic Achievements (\%)

\begin{tabular}{lccc}
\hline \multirow{2}{*}{ Communicational conditions } & \multicolumn{2}{c}{ Academic achievements } & Reliability of \\
\cline { 2 - 4 } & Up to 8 points & 8 to 10 points & differences p \\
\hline Rude service & 4.4 & 9.5 & 0.05 \\
\hline Slow service & 15.6 & 27.9 & 0.05 \\
\hline Unclear usage rules & 13.7 & 25.1 & 0.05 \\
\hline
\end{tabular}


The data presented in the table show that the higher the student's achievements, the more critical is his/her evaluation of the communicational conditions of the library as a learning environment.

The fifth block of questions was designed to reveal the aims of students' visits to the library, as well as their opinion about the physical conditions of the library as a learning environment. Answers to the questions were evaluated only by the following variants: totally agree or agree with the statement, and strongly disagree or disagree with the statement. According to the findings of the study, the greatest proportion of the subjects $(94.3 \%)$ indicated that they make copies of the needed material in the library, take books for a report, and also read newspapers or journals $(47.5 \%)$. Less frequently student come to the library to prepare for lectures and examinations (respectively, $36.2 \%$ and $24.2 \%$ of positive answers). This is because the subjects more frequently prepared for the examinations at home $(76.3 \%)$. It is noteworthy that first-year students more frequently, compared to third-year students, agreed with the statements that they prepared for examinations or tests in the library (respectively, 63.4\% and 41.3\%; $<<0.005$ ).

It was also determined that when a student does no know where to find important information, he/she most frequently applies to the library staff $(90.4 \%)$, the teachers $(85.2 \%)$, and friends $(76.4 \%)$. A part of students $(32.8 \%)$ thought that the library had a good information search system. Somewhat less of them $(21.7 \%)$ indicated that the library equipment guaranteed access to the global information resources. It is noteworthy that a small percentage of the subjects $(31.0 \%)$ stated that the library had the newest textbooks and teaching/learning means, and $42.1 \%$ of the subjects indicated that the ordering of publications from other libraries was not good. It was also found that the library had sufficient number of workplaces $(58.7 \%$ ), but as many as $67.3 \%$ of the respondents thought that the number of computerized workplaces was insufficient.

\section{Discussion}

The aim of the study was to determine the students' attitude to the conditions of a library as a learning environment, and to reveal the associations of this attitude with the duration of studies, time spent at the library, and students' achievements.

The study showed that students who spend more time in the library more positively evaluated the pragmatic conditions of the library as a learning environment, i.e. the application of modern information technologies and acquisition of newest literature. It was found that first-year students spend more time in the library, and thus we tend to think that they more positively, compared to third-year students, evaluate the aforementioned condition of the library as a learning environment. It is noteworthy that the study revealed associations between the aims of visits to the library and the duration of time spent there. It emerged that more first-year students, compared to third-year students, use the library for the preparation for examinations. It show that first-year students, compared to senior students, more identify with their higher educational institution, which is understandable since they are only starting their studies, while third-year students, according to the employment data, are more concerned with their professional activity.

Investigations by other researchers show that students are not satisfied with libraries as learning environments: for instance, some think that the area of the library should be increased since the library is becoming too small for storing all necessary sources of information (Arostegui, 2005), others (more than one-half of graduates) state that the 
number of books available in the library is insufficient, and their contents does not correspond to the variety of subjects of studies (Valiuškevičiūtè et al., 2005). On the other hand, the quality of the evaluated object depends on people's experience and interests (Wholey, 2001): if positive experience is acquired, a positive attitude is formed, and a decision is made that the evaluated object has reached high quality. However, if the majority state that a certain object is valuable, then it is really of a better quality than in case when only a minority of people see its advantages.

The study showed that students with higher academic achievements more frequently negatively evaluated the conditions of the library as a learning environment. Here we will ground our evaluations on the description of the personal competence of informational literacy presented by the American Association of Libraries (Owusu-Ansah, 2001). There it is stated that informational literacy is a person's ability to learn, which means that a person is familiar with the ways of the organization of information, is able to find the necessary information and knows how to use it; such person is ready for life-long learning, since he/she can always find information necessary for the performance of a certain task. Studies performed by other scientists show that the improvement in academic achievements entails the improvement of such informational literacy skills as the ability to find, to evaluate, to use, and to render information stored in different forms and media (Herring, 1998). It is noteworthy that the competence of informational literacy is analyzed together with library competence, computer and technological literacy, and ethical norms, as well as with critical thinking and communicational skills. We tend to think that the level of informational literacy in those who study successfully allows them to negatively evaluate the communicational conditions of the library as a learning environment.

Students who spend less time in the library and have lower academic achievements present negative evaluations of the pragmatic conditions of the library (i.e. newest literature or modern technologies). In this case one can discuss the studies on avoidance of visiting the library presented in scientific literature (Jiao and Onwuegbuzie, 1997; 1999). It is stated that libraries are less frequently visited by the groups of academic youth who experience various fears in such environment, the studies of these authors show that first-year students who visited an academic library for the first time, described their experiences and impressions used the word "fear" or its equivalents rather often, and the adjectives "stunned", "surprised", "baffled", "insecure", and "lost" were used most frequently. Mellon (1986) who performed the study called such feelings of students "library anxiety". The researcher determined that students who have library-associated fears are characterized by the following:

- They have a low evaluation of their abilities to use the services provided by the library;

- They experience shame and try to hide their inability to use library services;

- They think that their inability to use library services may become evident once they apply to the librarian.

Such people frequently think not only about their insufficient skills in using library services, compared to other students, but also that such drawback must be hidden as a source of difficulty. For this reason students frequently avoid asking questions to library personnel or other students for fear that their ignorance may be disclosed. Such avoidance may condition worse results of studies (Jiao and Onwuegbuzie, 1999). The described form of fear arising when a person comes to the library or is preparing to use its services 
most commonly manifests itself through negative emotions such as tension, scruple, insecurity, helplessness, self-defeating thoughts, and mental disorganization.

Students with worse academic achievements less frequently visit the library. Hence a question arises - maybe their achievements are worse because they do not use one of the learning environments that provides access to global information? For instance, Jiao and Onwuegbuzie (1997), using Bostick Library Anxiety Scale, deermined a significant negative association between library anxiety and frequency of visits to the library, i.e. students with high levels of library anxiety less frequently use the library compared to their less anxious colleagues. In other words, library anxiety impedes students' usage of library services to the extent that would be needed.

The study on the aims of visits to the library showed that less than one-half of the subjects used the library to prepare for various control tests and to perform the assigned tasks. Such results may be explained by the peculiarities of the studying process. According to the classical paradigm of education and training of specialists (which still predominates in higher educational institutions), students who learn and reproduce the information and assignments presented by the teacher learn more successfully (Riksaasen, 2001). Therefore we tend to think that students are not interested in deeper investigation of the ways the problems they analyze are solved in the world, and the ways the issues they study are discussed on the global level.

The interpretation of the findings of the study showed that an academic library as both the learning environment and an environment that empowers students for striving for professional qualification more or less improves future specialists both professionally, academically, and as personalities. The criterion of the effectiveness of the development of future specialists' competence may be considered to be the character of the experiences caused by preparations for examinations and various tests, preparation of projects, and the search for material created by the global academic community on the topic of interest. The character of such experiences may weaken the educational effect of the library. The improvement of learning environments should be based on the opinion of students who have better academic achievements and spend more time in the library.

\section{Conclusions}

The findings of the research on students' experiences while in the library show that the educational role of a library in the education and training of future specialists is weakened by the communicational conditions of the library, especially such manifestations of these conditions as rude and slow service, and unclear usage rules. Students with better academic achievements presented a more critical evaluation of the aforementioned manifestations of the communicational conditions. They like as first-year students spent more time in the library. It is noteworthy that students who rarely use the services of the library were more frequently dissatisfied with the library staff's working culture.

The analysis of the subjects' evaluations of the academic library showed that students present best evaluations of such variables of the pragmatic conditions of the library as the source of knowledge (precise information may be obtained here), and a place for independent studies; the variable of the communicational conditions - the professional level of the personnel - was also evaluated positively. Poorer evaluations were presented concerning the manifestations of the pragmatic conditions of the library - newest literature and modern technologies, and concerning the manifestation of the physical conditions of the library - comfortable workplaces. 


\section{References}

Arostegui, J. L. (2004). Uncovering contradictions in evaluation: The case of the music education programme at the university of Granada. The Quality of Higher Education, $1,138-158$.

Herring, J. (1998). Informaciniu igūdžiu ugdymas mokykloje. Vilnius: Garnelis.

Holmes, G., Hooper, N. (2000). Core competence and education. Higher Education, 40, 247-258.

Jiao, Q. G., \& Onwuegbuzie, A. J. (1997). Antecedents of library anxiety. Library Quarterly, 67(4), 372-389.

Ilisko, Dz., Igatjeva, S., \& Micule, I. (2010). Teachers as researchers: Bringing teachers' voice to the educational landscape. Journal of Teacher Education for Sustainability, $12,51-66$.

Jiao, Q. G., \& Onwuegbuzie, A. J. (1999). Identifying library anxiety through students' learning-modality preferences. Library Quarterly, 69(2), 202-216.

Johnston, B., \& Webber, Sh. (2003). Information literacy in higher education: A review and case study. Studies in Higher Education, 28(3), 336-352.

Lea, S. J., Stephenson, D., \& Troy, J. (2003). Higher education students' attitudes to student-centred learning: Beyond "educational bulimia"? Studies in Higher Education, 28(3), 321-334.

Mellon, C.A. (1986). Library anxiety: A grounded theory and its development. College \& Research Libraries, 47, 160-165.

OECD. (2002). Reviews of National Policies for Education. Lithuania. Paris: Routledge.

Owusu-Ansah, E.K. (2001). The academic library in the enterprise of colleges and universities: toward a new paradigm. Journal of Academic Librarianship, 27(4), 282295.

Prosser, M., Ramsden, P., Trigwell, K., \& Martin, E. (2003). Dissonance in experience of teaching and its relation to the quality of student learning. Studies in Higher education, 28(1), 37-48.

Salite, I. (2008). Educational action research for sustainability: Constructing a vision for the future in teacher Education. In Journal of Teacher Education for Sustainability, 10, 5-17.

Wholey, J. S. (2001). Defining, improving, and communicating program quality. In A. P. Benson, D. M. Hinn \& C. Lloyd (Eds.), Advances in program evaluation (pp. 201-216). Bingley: Emerald Group Publishing Limited. 